\title{
Preparation and Tribological Performance Testing of Bonded Solid Lubricating Coatings Used on Spherical Plain Bearings
}

\author{
Rui ZHANG ${ }^{1, a}$, Ming QIU ${ }^{1,2, b, *}$, Ying-Chun $\mathrm{LI}^{1, \mathrm{c}}$ and Da-Wei ZHOU ${ }^{1, \mathrm{~d}}$ \\ ${ }^{1}$ School of Mechatronics Engineering, Henan University of Science and Technology, Luoyang, \\ 471003, China \\ ${ }^{2}$ Collaborative Innovation Center of Machinery Equipment Advanced Manufacturing of Henan \\ Province, Luoyang, 471003, China \\ a13007565231@163.com \\ bqiuming69@126.com \\ clyc2004henan.china@126.com \\ d782024465@qq.com \\ *Corresponding author: Ming Qiu. E-mail: qiuming69@126.com,Tel:13653791900.
}

Keywords: Solid lubricating coating, Spherical plain bearing, PTFE; $\mathrm{MoS}_{2}$, Friction and wear.

\begin{abstract}
To solve the lubricating problems of spherical plain bearings under high-low temperature, high vacuum, heavy loads and strong oxidation conditions, the PTFE and $\mathrm{MoS}_{2}$ based lubricating coatings were prepared on the inner rings of the spherical plain bearings by spraying technique. A self-made tribo-tester was used to investigate the friction coefficient, wear loss, and friction temperature increase of bearings with coatings under different oscillation frequencies. Using scanning electron microscope (SEM) and energy dispersive X-ray spectroscopy (EDS), the worn surfaces of the coatings and the counter surfaces were characterized and analyzed. The results showed that PTFE and $\mathrm{MoS}_{2}$ based lubricating coatings significantly improved the tribological properties of the spherical plain bearings. The tribological performance of PTFE based coating was obviously superior to $\mathrm{MoS}_{2}$ based coating and its wear mechanism was adhesive wear. However, the $\mathrm{MoS}_{2}$ based coating mainly occurred severe adhesive wear and abrasive wear, and the tribological properties of spherical plain bearings with $\mathrm{MoS}_{2}$ coating were relatively optimal under low frequencies. This paper provides a reference to developing new lubricating techniques for the spherical plain bearings.
\end{abstract}

\section{Introduction}

Bonded solid lubrication coating is an effective solution to solve the lubrication and wear problems under harsh conditions of high-low temperature, high vacuum, heavy loads and strong oxidation conditions. Remarkable achievements have been made in many high technology fields [1-3]. Compared with thermal spraying [4-5], laser cladding [6], thin film deposition [7,8] and other technologies, the preparation process of adhesive solid lubricant coating is undoubtedly the most economical and feasible [9-10]. Bonded solid lubrication coating is not only economical but also excellent in tribological properties. Currently, more than $95 \%$ of the lubricating materials achieve the lubrication performance through spraying technology to reduce the friction and wear [11]. Molybdenum disulfide $\left(\mathrm{MoS}_{2}\right)$ has the six-party crystal structure formed by S-Mo-S covalent, which is similar to the "sandwich layer", and easily to slip and transfer into lubricant film on the contact surfaces [12] and its application in sliding contact surface can reduce the wear degree of the structure [13-14]. However, pure $\mathrm{MoS}_{2}$ coatings in the wet air environment present is easy to be oxidized and leads to low hardness, resulting in poor wear resistance and limited application [1516]. Polytetrafluoroethylene (PTFE) is widely used as a solid lubricant because of its excellent selflubricating property, low friction coefficient, thermal stability and chemical stability. But PTFE as wear-resistant materials can't be used alone because of its low mechanical strength, poor wear resistance, and cold flow phenomenon [17-19]. The tribological performance of the organic solvent 
type bonded solid lubrication coating can get obvious improvement by adding some filler which has the lubricant synergistic effect, such as adding graphite in the $\mathrm{MoS}_{2}$ lubricant, filling additional $\mathrm{MoS}_{2}$ [20], Ni, $\mathrm{Al}_{2} \mathrm{O}_{3}$ [21] in PTFE lubricant. This paper prepared PTFE based coatings and $\mathrm{MoS}_{2}$ based coatings on the inner rings of spherical plain bearings respectively. Tribological properties of the coatings were tested by a self-made tribo-tester under three different oscillation frequencies. The morphologies of the worn surfaces were characterized and analyzed by SEM and EDS.

\section{Experimental Procedure}

\section{Materials}

The particle size of PTFE and $\mathrm{MoS}_{2}$ as solid lubricant are respectively $0.2 \mu \mathrm{m}$ and $15 \mu \mathrm{m}$. Epoxy resin(E-44) and polyamide (650) were supplied by Luoyang Shuangrui Anti-corrosion Engineering Technology Co., Ltd, China. Xylene, n-butyl alcohol, and fluorocarbon surfactant were purchased from Beijing Fenghua Chemical Reagent Factory, China. Dispersant(BYK-104) was provided by Pasto Shenzhen Chemical Industry Co., Ltd, China. The GE20ET-2RS test spherical plain bearings (GCr15 steel) were supplied by Taizhou Kejin bearing Co., Ltd, China.

\section{Preparation of the Coating}

The adhesive system adopts the combination of the binder, the curing agent, the solid lubricant and the solvent. PTFE and $\mathrm{MoS}_{2}$ were used as solid lubricants in the PTFE based coating with the weight ratio of 1:1. Graphite and $\mathrm{MoS}_{2}$ were used as solid lubricants in the $\mathrm{MoS}_{2}$ based coating with the weight ratio of 1:3. E-44 epoxy resin was used as a binder with the same amount as curing agent polyamide 650 in the experiment, and the solvent was a mixed solution of xylene and butyl alcohol.

Firstly, epoxy resin was weighed according to the formula, then the desired amount of lubricant was added into epoxy resin with a glass rod fully mixing at a $300 \mathrm{r} / \mathrm{min}$ for $5 \mathrm{~min}$. After the addition of the solvent, a ZLD-300 high-speed agitator was used for stirring at $1200 \mathrm{r} / \mathrm{min}$ for $40 \mathrm{~min}$ or longer. One or two drops of dispersant were dropped into the system at the beginning of stirring to promise the homogeneous distribution of the components. The curing agent was mixed at last, and the solution needed to be exposed to the air for a proper time to ensure the fully volatile of the gas in the liquid. The inner rings of the spherical plain bearing used as the substrate material were washed with acetone solution and preheated under $100^{\circ} \mathrm{C}$ for $5-7 \mathrm{~min}$ before spraying. Then the coating was sprayed with an $\mathrm{H}-2000$ gun under the pressure of $0.2 \mathrm{MPa}$ and at a distance of about 300 to $400 \mathrm{~mm}$. The coating thickness was $25 \sim 35 \mu \mathrm{m}$. Then the sample was cured in the BPG9030AH electric furnace. The curing temperature and dwell time for PTFE based coating was $120{ }^{\circ} \mathrm{C} / 40 \mathrm{~min}$ and that of $\mathrm{MoS}_{2}$ based coating was $150{ }^{\circ} \mathrm{C} / 90 \mathrm{~min}$. And a schematic of the prepared self-lubricating plain bearing with the coating is shown in Fig. 1a.

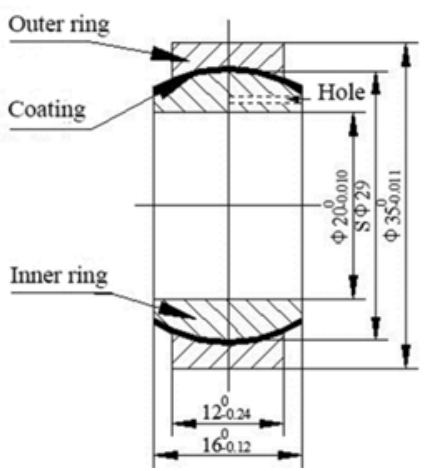

(a)

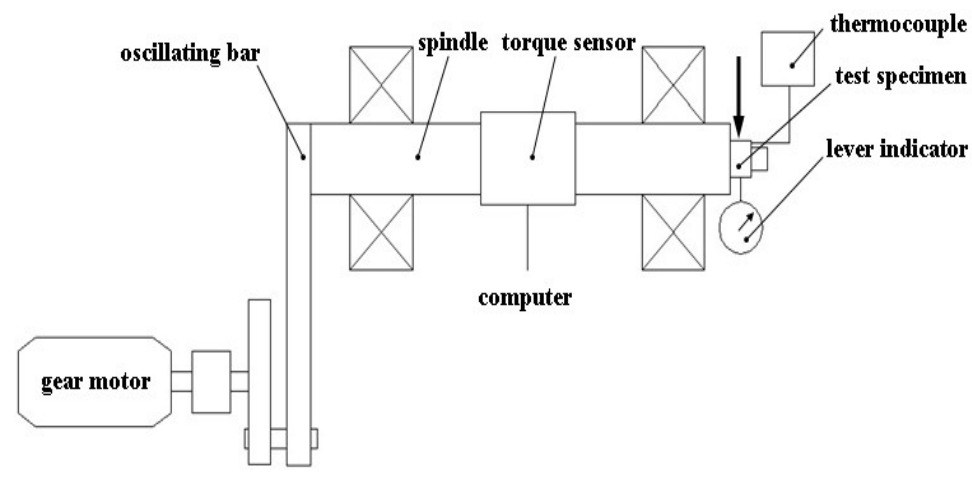

(b)

Fig. 1 Schematics of the tribo-tester and the test bearings. 


\section{Test Method}

The tribological properties of bearings with coatings were tested by a self-made tribo-tester(Fig. $1 \mathrm{~b}$ ). The test condition were as follows: the swing angle of $\pm 10^{\circ}$, the swing cycles of $2.5 \times 10^{4}$, the applied load of $25 \mathrm{MPa}$, the swing frequency of 2, 2.5, and $3 \mathrm{~Hz}$, which was established referred to the U.S. military standards SAE AS81819 and SAE AS81820. The scanning electron microscope (SEM) was used to observe microstructure and morphology of the coatings. The chemical composition of the coatings and film-formation were analyzed by an energy dispersive X-ray spectroscopy (EDS).

\section{Test Results and Analysis}

\section{Tribological Properties of the Spherical Plain Bearing}

Fig. 2 shows the tribological performance curves of the bearings under $25 \mathrm{MPa}$ loading pressure. In Fig. 2a, with the increase of the oscillation frequency, the friction coefficient of bearings decreased whether with PTFE based coating or not, whereas the friction coefficient of bearings with $\mathrm{MoS}_{2}$ based coating increased firstly and decreased subsequently. The friction coefficient of bearings with PTFE based coating was smaller under three swing frequencies compared with that of bearings with $\mathrm{MoS}_{2}$ based coating. The friction coefficient of the bearings without coating was the highest. The relative wear resistance of the bearing with coating was obviously higher than that of the bearing without coating. The relative wear resistance of bearings with PTFE based coating increased with the increase of the swing frequency. However, bearings with $\mathrm{MoS}_{2}$ based coating had an opposite trend. The relative wear resistance of bearings with PTFE based coating was higher than that of bearings with $\mathrm{MoS}_{2}$ based coating under three different swing frequencies. Fig. 2c shows that there was a positive correlation between the temperature increase of three bearings and the swing frequency. The temperature increase of bearings without coating was higher than that of bearings with the coating. The overall change trend of temperature increase of bearing with PTFE based coating was the least. The temperature increase of bearings with $\mathrm{MoS}_{2}$ based coating was lower than that of bearings with PTFE based coating at low frequencies (below 2.5Hz).

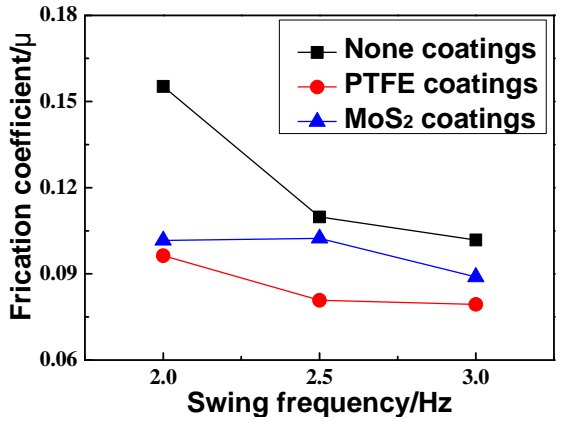

(a)Friction coefficient

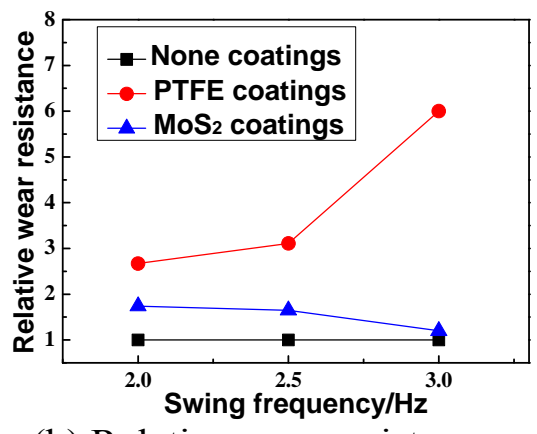

(b) Relative wear resistance

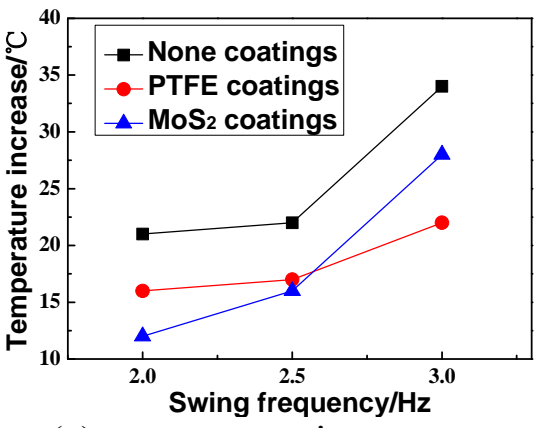

(c) temperature increase

Fig. 2 Tribological performances of self-lubricating bearings vs. swing frequency $(P=25 \mathrm{MPa}$, $N=25000$ )

\section{Analysis of the wear mechanisms}

Fig. 3a shows the microscopic picture of the inner rings of spherical plain bearings without coating after abrasion, a large number of folds and obvious furrow that caused by shear of debris formed on the wear surface and spalling pit appeared in the local position. Phosphate film on the surface of the inner ring had been destroyed, resulting in the exposure of the substrate, which indicated that abrasive wear and adhesive wear occurred on the inner ring. As is shown in Fig. 3d, the phosphate film on the outer ring had been destroyed heavily, and a lot of shedding material transformed into debris after peeling off the worn surface, indicating the severe abrasive wear . 
Fig. $3 \mathrm{~b}$ shows the microscopic picture of the inner rings of spherical plain bearings with PTFE based coating after abrasion. Smooth-wearing surface and dense zone with sparse holes were observed from the microscopic pictures. The dense region was the transfer film which formed after the interruption of the PTFE and adhesive molecular polymeric chain. With the transformation of the solid lubricant of the wear interface strengthening dynamically, so efficient the lubricating effect was that the wear rate decreased. Adhesion wear occurred, and uniform and continuous transfer film formed on the counter surface (Fig. 3e)with good tightness. From the EDS of the inner ring of the bearing with PTFE based coating in Fig. $3 \mathrm{~g}$, it can be seen that a lot of elements such as F, S, Mo and a small amount of $\mathrm{P}$ appeared on the surface of the coating, indicating the good quality of coating surface. And lubrication film had not been destroyed. Fig. 3h is the EDS for the outer ring. It contained a large amount of Fe. S, Mo, and F, which may transferred from the coating bonded to the inner ring, formed transfer film and protected the bearing well.
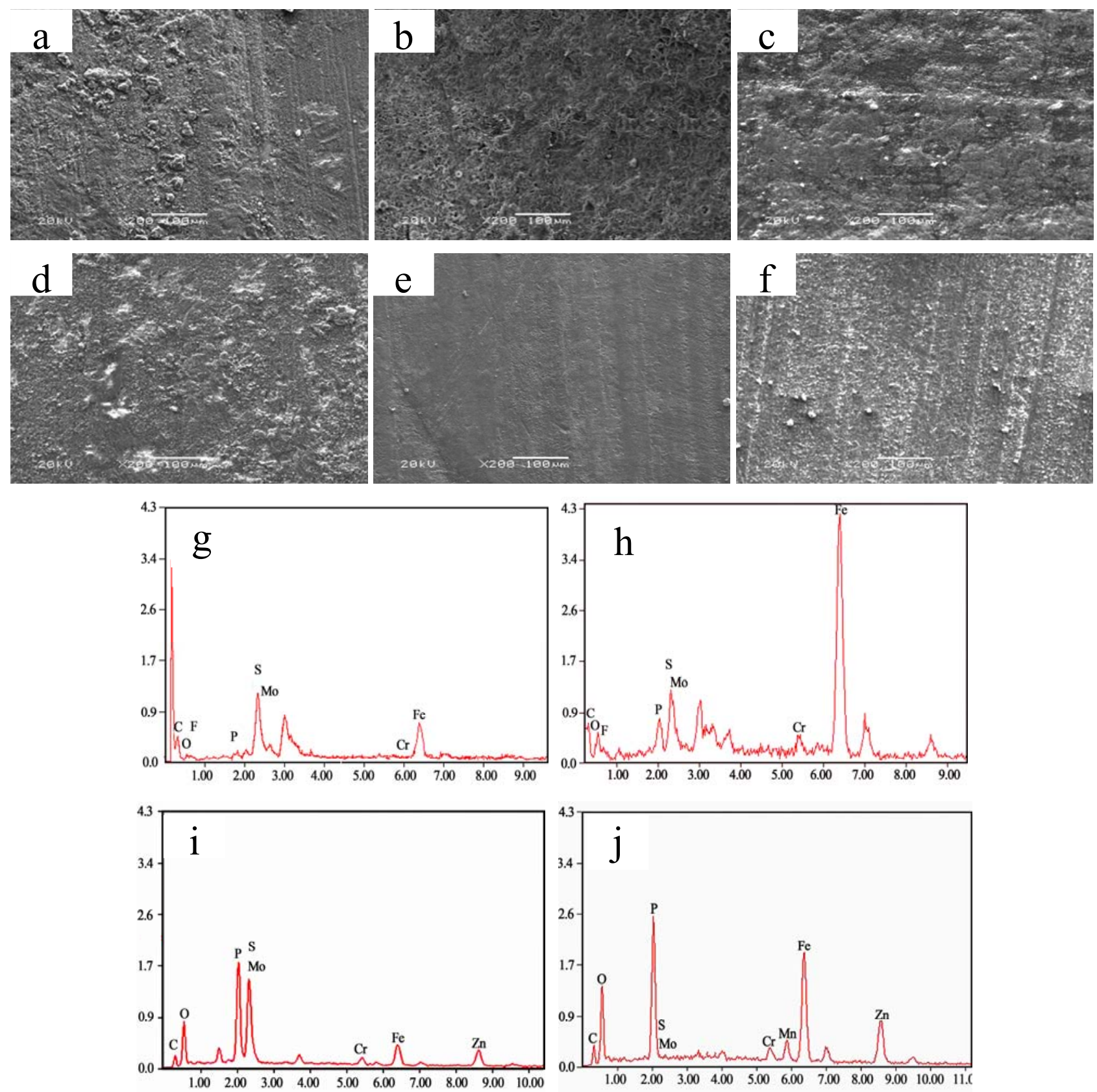

Fig. 3 SEM morphologies and EDS of the worn surfaces for bearings without coatings(inner ring:a(SEM);outer ring:d(SEM)), with PTFE based coatings(inner ring:b(SEM),g(EDS);outer ring:e(SEM), h(EDS)), with $\mathrm{MoS}_{2}$ based coatings(inner ring:c(SEM),i(EDS); outer ring:f(SEM),j(EDS)) 
Fig. 3c shows the microscopic picture of the inner rings of bearings with $\mathrm{MoS}_{2}$ based coating. Obviously, the coating surface had been destroyed seriously, and a large number of particles fell off from the worn surface and formed wear debris. Severe adhesive wear and abrasive wear occurred. Fig. $3 \mathrm{i}$ shows that large quantities of phosphorus, sulfur, and molybdenum existed on the surface, a little oxygen carbon and iron were also observed, of which the content of phosphorus was the highest as the result of exposing of the phosphate film after the long-time friction. The coating was damaged under such condition and adhesion wear occurred. Fig. $3 \mathrm{f}$ and Fig. $3 \mathrm{j}$ shows the microscopic picture and EDS of the worn surface, the outer ring surface contained phosphorus, zinc, and chromium, especially the high content of an iron element, but the content of sulfur and molybdenum was rare. It revealed that no obvious transfer film formed on the surface of the outer ring in the test process, and the counter surface had not been effectively protected. After a long time of friction, the phosphate film on the outer ring was destroyed and even led to the exposing of a large area of the substrate, which was confirmed from the iron content in the EDS. The outer ring surface had obvious furrow caused by the micro cutting, indicating the abrasive wear.

PTFE based coating is easy to form a uniform and continuous transfer film on the dual surfaces for two reasons: first, no branched chains exist in the molecules, and the molecules are only bound by the van Edward force, which is easy to move along the slip direction and transfer to the counter surface. Second, with the tendency of complexation with metal, metal fluoride and organometallic complex exists on the friction metal surface. With the comparison of the worn surface morphology of the PTFE based coating, large tracts of white matter appeared on the worn surface of the $\mathrm{MoS}_{2}$ based coating. $\mathrm{MoS}_{2}$ was prone to be oxidized to $\mathrm{MoO}_{3}$ after the long-term friction, an increase in brittleness accompanying with oxidation of the $\mathrm{MoS}_{2}$ crystals, which led to the occurrence of the ruptures and detachments of the plastic flow layers and reduced the abrasion resistance of the coating surface. It can be revealed that the solid lubricant coating on the surface of the friction dual surface played a significant role in the protection of spherical plain bearing. The lubrication effect of $\mathrm{MoS}_{2}$ based coating for spherical plain bearing was inferior to the PTFE based coating.

\section{Summary}

(1) Abrasive wear and adhesive wear occurred on the counter surface of non-spraying spherical plain bearings, whereas PTFE based coating played a significant role in the protection and lubrication for the spherical plain bearing. Only slightly adhesive wear occurred and much transfer film formed in the wear process. Severe adhesive wear and abrasive wear were observed from the surfaces of the spherical plain bearing with $\mathrm{MoS}_{2}$ based coating.

(2) The oxidation of $\mathrm{MoS}_{2}$ led to an increase in brittleness and occurrence of the ruptures and detachments of the plastic flow layers. As a result, the lubrication and protective effect of $\mathrm{MoS}_{2}$ based coatings were inferior to PTFE based coatings.

(3)The tribological performance of the steel/steel friction pair of the spherical plain bearing was improved obviously under the protection of the PTFE based coating and the $\mathrm{MoS}_{2}$ based coating. The tribological performance of the spherical plain bearing with PTFE based coating was obviously better than that with $\mathrm{MoS}_{2}$ based coating, except low swing frequencies.

\section{Acknowledgments}

The authors are grateful for financial support from the National Natural Science Foundation of China (Grant No.51275155), National High-tech R\&D Program of China (No. 2015AA043004), and Outstanding Talent Fund Projects in Henan Province (No. 154200510013).

\section{References}

[1] H. Z, J. Z, Q.P. W, et al, The effect of Ti content on the structure land mechanical properties of $\mathrm{MoS}_{2}$-Ti composite coatings deposited by unbalanced magnetron sputtering system, Physics, Procedia,18(2011)234-239. 
[2] J.M. Chen, Y.P. Ye, H.X. Dang, Developing situation and application of bonded solid lubricant films, Tribology, 1994, 14(2):180-189(in Chinese)

[3] Z.G. Zang, Atsushi Nakamura, Jiro Temmyo, Single cuprous oxide films synthesized by radical oxidation at low temperature for PV application, Opt. Express, 21(9)(2013)11448-11456.

[4] C. Sun, L. Guo, G.X. Lu, et al, Interface bonding between particle and substrate during HVOF spraying, Applied Surface Science, 317 (2014) 908-913.

[5] A.H. Pakseresht, M.R. Rahimipour, M.R. Vaezi, et al, Effect of splat morphology on the microstructure and dielectric properties of plasma sprayed barium titanate films, Applied Surface Science, 324 (2015) 797-806.

[6] R. Zhu, Z.Y. Li, X.X. Li, et al, Microstructure and properties of the low-power-laser clad coatings on magnesium alloy with different amount of rare earth addition, Applied Surface Science, 353 (2015) 405-413.

[7] Y.X. Wu, J.M. Chen, H.X. Li, et al, Preparation and properties of Ag/DLC nanocomposite films fabricated by unbalanced magnetron sputtering, Applied Surface Science, 284 (2013) 165-170.

[8] N.R. He, L. Ji, X.H. Liu, et al, Role of annealing temperatures on the evolution of microstructure and properties of $\mathrm{Cr}_{2} \mathrm{O}_{3}$ films, Applied Surface Science, 357 (2015) 1472-1480.

[9] N. Hiraoka, Wear life mechanism of journal bearings with bonded $\mathrm{MoS}_{2}$ film lubricants in air and vacuum, Wear, 249 (2002) 1014-1020.

[10] H.B. Qiao, Q. Guo, A.G. Tian, et al, A study on friction and wear characteristics of nanometer $\mathrm{Al}_{2} \mathrm{O}_{3} / \mathrm{PEEK}$ composites under the dry sliding condition, Tribology. International, 40 (2007) 105-110.

[11] Charles J Beall. Solid film lubricants, Metal Finishing, 2000, (98): 513-514.

[12] T.W. Scharf, P.G. Kotula, S.V. Prasad, Friction and wear mechanisms in $\mathrm{MoS}_{2} / \mathrm{Sb}_{2} \mathrm{O}_{3} / \mathrm{Au}$ nanocomposite coatings, Acta Materialia, 58 (2010) 4100-4109.

[13] P.M. Ashraf, S.M.A. Shibli, Reinforcing aluminium with cerium oxide: a new and effective technique to prevent corrosion in marine environments, Electrochemistry Communications, 9(2007)443-448.

[14] B.P. Mosher, C.W. Wu, T. Sun, et al, Particle-reinforced water-based organic-inorganic nano composite coatings for tailored applications, J. Non-Cryst. Solids, 352(2006)3295-3301.

[15] J.M. Chen, Y.P. Ye, H.X. Dang, Developing situation and application of bonded solid lubricant films, Tribology, 14(1994)180-189.

[16] H. Zhou, J. Zhu, Q.P. Wang, The effect of Ti content on the structura land mechanical properties of $\mathrm{MoS}_{2}-\mathrm{Ti}$ composite coatings deposited by un-balanced magnetron sputtering system, Physics Procedia, 18(2011)234-239.

[17] S. Beckforda, M. Zou, Wear resistant PTFE thin film enabled by a poly dopamine adhesive layer, Applied Surface Science, 292 (2014) 350-356.

[18] J. Khedkar, I. Negulescu, E.I. Meletis, Sliding wear behavior of PTFE composites, Wear, 252 (2002) 361-369.

[19] S. Zhang, G.L. Lia, H.D. Wang, et al, Impact of nanometer graphite addition on the antideliquescence and tribological properties of Ni/MoS 2 lubricating coating, Physics Procedia, 50 (2013) 199-205.

[20] S. Rossi, F. Chini, G. Straffelini, et al, Corrosion protection properties of electroless nickely/PTFE, phosphatey/MoS 2 and bronze/PTFE coatings applied to improve the wear resistance of carbon steel, Surface and Coatings Technology. 173 (2003) 235-242. 
[21] A.G. Tang, M.L. Wang, W. Huang, X.L. Wang, Composition design of Ni-nano- $\mathrm{Al}_{2} \mathrm{O}_{3}-\mathrm{PTFE}$ coatings and their tribological characteristics, Surface \& Coatings Technology, 282 (2015) 121-128. 